The BDJ News section accepts items that include general news, latest research and diary events that interest our readers. Press releases or articles may be edited, and should include a colour photograph if possible. Please direct your correspondence to the News Editor, Arveen Bajaj at the BDJ, The Macmillan Building, 4 Crinan Street, London N1 9XW or by email to bdj@bda.org

\section{CPD in aid of the developing world}

Oral health aid charity Dentaid is running a unique CPD Day at King's College London on Saturday 15th October 2005. Three speakers will be giving five hours of quality, verifiable CPD on a range of topical and clinically useful subjects, with all proceeds going to improve oral health in the developing world.

Martin Kelleher, consultant in Restorative Dentistry at Guys, Kings \& St Thomas's, will be speaking on 'The Worn Tooth? The Whole Tooth? Or Nothing of the Tooth? So help me!', in which he will be teaching hot tips in the latest restorative techniques.

Kevin Lewis, associate editor of Dental Practice and dental director of Dental Protection, will be lecturing on 'Reasons to be cheerful?' in relation to the current dental industry and Mark McGurk, head of the department of Oral and Maxillofacial Surgery at Guy's Hospital, will be lecturing on 'Diagnostic Dilemmas in the Mouth and Jaws.' The speakers are giving their time for free with all proceeds from the day going towards Dentaid's work in improving oral health in the developing world. Dentaid is a UK based registered charity, started in 1996. The charity has supplied specialist aid and support to over 100 dental and oral health projects in nearly 50 countries worldwide.

Resourcing charitable dental clinics, supporting and encouraging school prevention programmes, training key personnel and providing culturally appropriate oral health for under-served and marginalised communities are just a few of the ways the charity is working. As part of the CPD Day, Dentaid's Chief Executive Luke Wordley, will also be making a short presentation about oral health in other parts of the world and Dentaid's work. Further information can be found at www.dentaid.org.

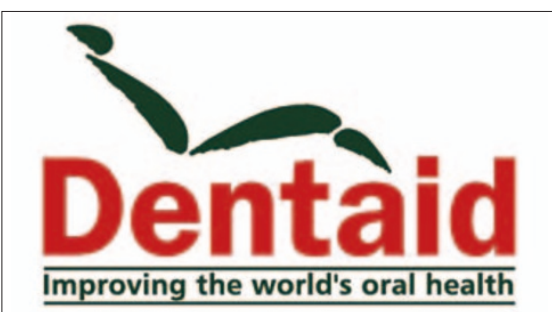

\section{Double first for overseas practice}

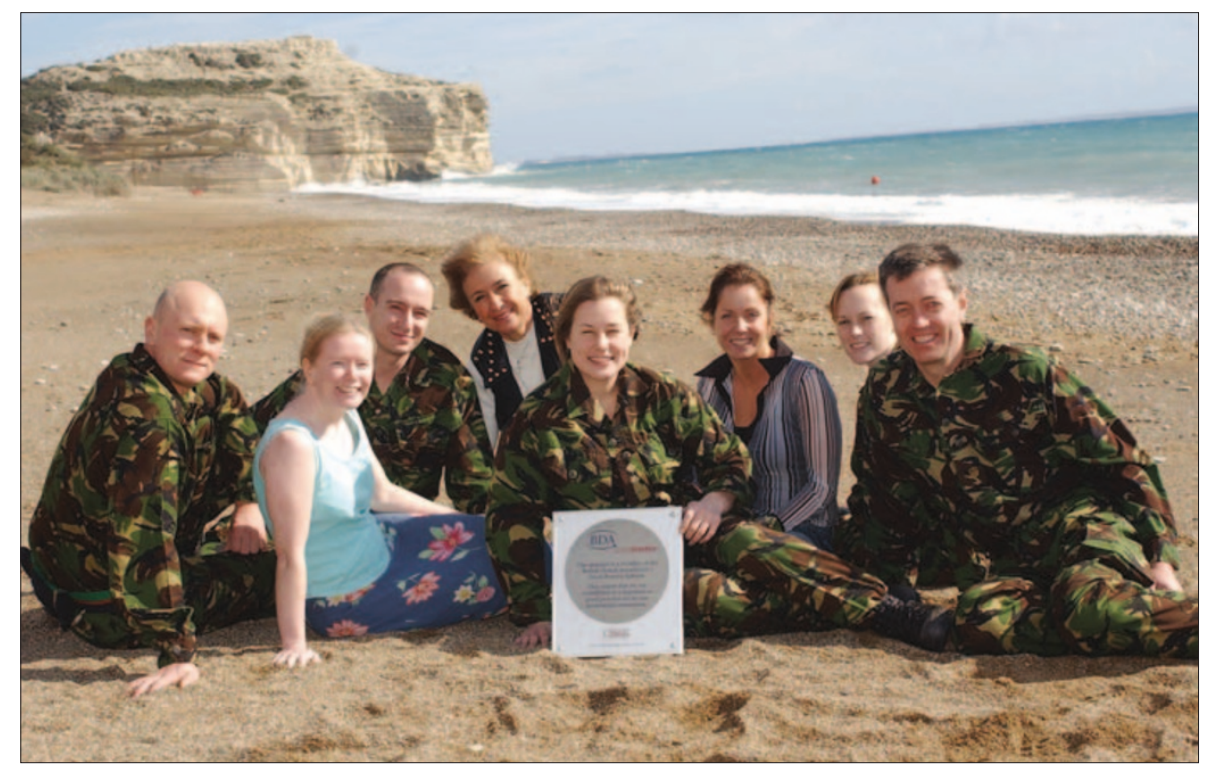

Dental Centre Episkopi in Cyprus has become both the first military and first overseas practice to achieve BDA Good Practice Scheme accreditation. The Dental Centre is one of the four Defence Dental Agency (DDA) practices in Cyprus which provide care for the British military community. Episkopi has a population of 2500 comprising well over 1000 service personnel, their families and supporting organisations. It is the headquarters of the British Sovereign Base Area on the island so civil servants are also entitled to receive treatment.

The DDA's priority is maintaining the health of the soldiers to minimise the risk of them developing problems whilst on operations, such as in Iraq, which would impact adversely on their military effectiveness. Civilians are treated comparably to UK general practice. An increasing number of military families have experienced difficulty accessing NHS dentistry back home and are now making use of the services available in Cyprus.

\section{BDA's Chief Executive stands down}

British Dental Association Chief Executive Ian Wylie will be leaving the BDA at the end of the year. Mr Wylie, who has been at the BDA for almost five years, will leave in December to take up health consultancy and teaching work in Hong Kong. Speaking of his decision, he said, "These five years at the BDA have been professionally and personally enjoyable and fulfilling. I am very grateful to all the staff of the BDA for their support during this time. I am also grateful to the Executive Board and the wider BDA membership for allowing me the privilege of holding the office of Chief Executive." 


\section{New FDI President- Elect}

Dr Burton Conrod of the Canadian Dental Association was elected as President-Elect of the FDI at the recent Montreal Annual World Dental Congress, defeating the BDA's nominated candidate, former Chief Executive John Hunt. Dr Conrod will begin a two-year term as FDI president in 2007, following Dr Michèle Aerden of Belgium.

The voting was complicated by the fact that, aside from the election for President-Elect there was also an election for Council members. Otherwise, the BDA delegation including John Renshaw, Susie Sanderson, Gordon Watkins, Lester Ellman and Stuart Johnson successfully represented the BDA with Stuart narrowly missing being elected to the Practice Commission on his first attempt. The Congress was hailed as very successful with 15,000 plus registrants. Next year it moves to China, followed by Dubai in 2007 and the newly announced Stockholm in 2008.

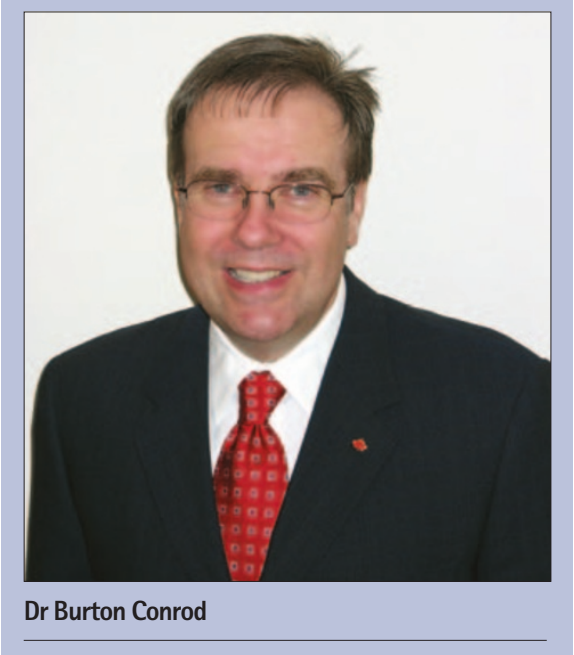

\section{Quit smoking to save teeth}

Smokers who give up are much less likely to lose their teeth prematurely than those who don't kick the habit, according to research conducted at the University of Newcastleupon-Tyne. Dental researchers observed a group of cigarette smokers with chronic gum disease over one year and found some symptoms were more likely to improve in the people who quit during the study period.

The researchers' findings were revealed in the Journal of Clinical Periodontology, and the study, The effect of quitting smoking on chronic periodontitis by PM Preshaw et al, followed 49 smokers with chronic gum disease over one year. All were encouraged to stop smoking through counselling and, in some cases, using nicotine replacement therapy and/or medication. All of the patients also received treatment for their gum disease. One-fifth of the patients quit smoking, and in those patients, gum health was significantly improved compared to those who continued to smoke over the 12 months.

Dr Philip Preshaw a clinical lecturer in periodontology with Newcastle University's School of Dental Sciences, led the research. He said, "Our study shows that people should stop smoking now if they want to increase their chances of keeping their teeth into old age. Dentists have known for some time that smokers have worse oral and gum health than non-smokers but for the first time we have shown that quitting smoking together with routine gum treatment results in healthier gums."

The Department of Health has promoted the idea of smoking cessation counselling by dentists, and dental students at Newcastle University are now taught how to counsel patients on this issue as part of their degree course.

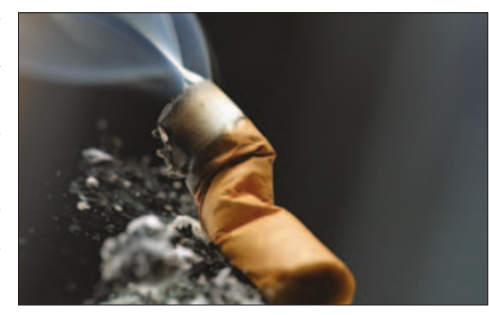

\section{Chairman and Vice Chairman re-elected}

The Dentists' Provident Society has announced the re-election of Martin Mace as Chairman and Julian Scott as Vice Chairman, following its recent Annual General Meeting. Dr Mace has been a Member of the Society's Committee of Management since 1982 and has been a Consultant in Oral and Maxillofacial Surgery at Stoke Mandeville Hospital since 1978. He now has private oral and maxillofacial practices in London and Buckinghamshire. Dr Scott has been a member of the Committee of Management since 1987 and has served on the Society's audit sub-committee since 1997. He became a Clinical Probity Officer with the Dental Practice Board in 2000 and was previously in general practice for 27 years.

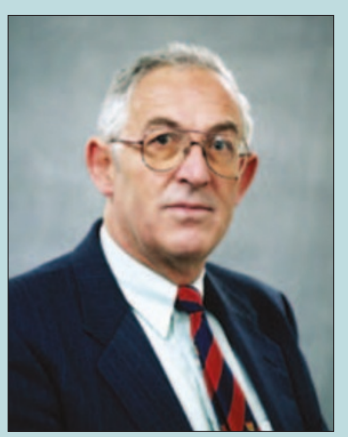

Julian Scott

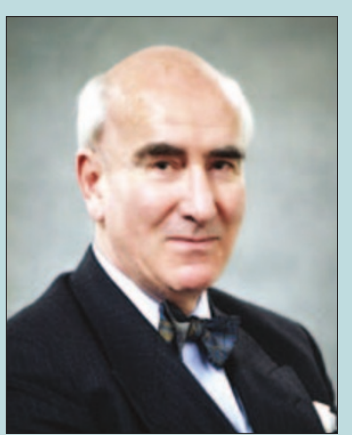

Martin Mace 


\section{Heart surgery and oral health views assessed}

At risk heart patients do not accept the link between their oral health and their general health according to research to be published in the next issue of the BDJ. Hearts and mouths: perceptions of oral hygiene by at-risk heart surgery patients by RJ Lowry et al assessed the attitudes of patients who are placed at risk after valvular heart surgery due to the connection between poor oral hygiene, valvular heart disease/surgery and the risk of developing infective endocarditis.

A qualitative focus group design based study was carried out on subjects at three months' post heart surgery. The results showed a desire by most patients to talk about their experiences but found that patients did not accept the link between their oral health and their general health and that oral hygiene practices were not necessarily oral health related.

There were mixed views on what determined oral hygiene behaviour. Some participants thought they brushed their teeth for health reasons, but others thought grooming or ritualistic behaviour was the predominant reason they practised oral health care. The authors believe the findings show the need to introduce the oral health professional at an early stage as a part of the hospital team itself, endorsed by the surgeon to enhance their credibility and status. RJ Lowry commented, "We believe oral health promoters can devise successful interventions on the basis of this information." It is hoped that oral health care professionals will be able to devise interventions that are successful using the research data.

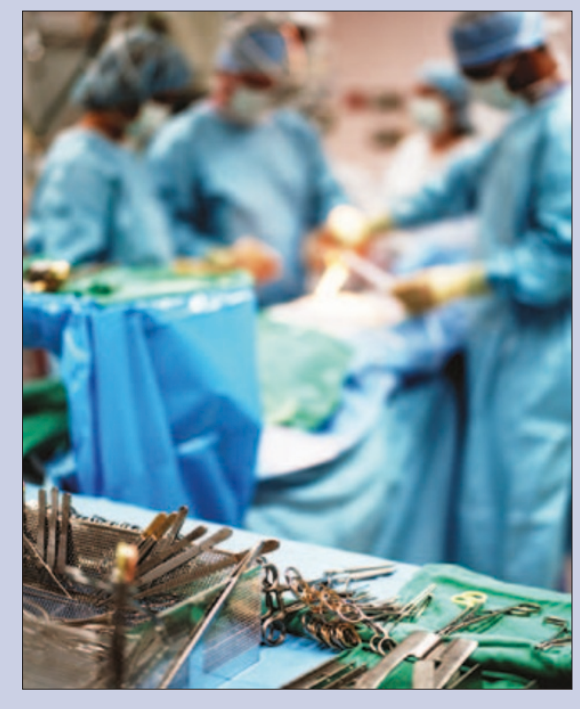

\section{C-section babies at risk of poorer oral health}

A new study by New York University (NYU) dental researchers suggests that women with dental caries who deliver Caesarean-section babies should pay special attention to their newborns' oral health.

The NYU researchers focused on a caries-causing bacterium that mothers with caries transmit to their newborns. The bacterium Streptococcus mutans, grows on tooth surfaces and interdentally, where it multiplies and converts foods, especially those containing sugar and starch, into acids that begin the demineralisation cycle leading to caries.

C-section deliveries were infected by the bacterium almost a year earlier than vaginally-delivered infants in the four-year study of 156 mother-infant pairs published in the September issue of the Journal of Dental Research. The first signs of the bacterium appeared at an average of 17.1 months of age in C-section babies, compared to 28.8 months in vaginally-delivered infants. The findings suggest that moth-

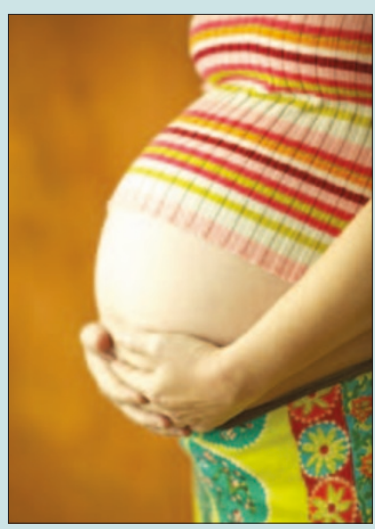
ers who have dental caries should inform their family dentists if they had a C-section delivery because of the potentially higher risk that the child will also develop caries, said the study's principal investigator, Dr Yihong $\mathrm{Li}$, an Associate Professor of Basic Science and Craniofacial Biology at NYU College of Dentistry.

"Vaginally-delivered infants offer oral bacteria a less hospitable environment," Dr Li explained. "They develop more resistance to these bacteria in their first year of life, in part because of exposure to a greater variety and intensity of bacteria from their mothers and the surrounding environment at birth. C-section babies have less bacterial exposure at birth, and therefore less resistance."

\section{DIARY}

October 2005

BDA Metropolitan Branch: Spot the Composite Date: 01.10 .05

Venue: British Dental Association, London Tel: 01943604400

British Dental Trade Association International

Dental Showcase 2005

Date: 06-08.10.05

Venue: NEC Birmingham

Tel: 08702413365

www.dentalshowcase.com

146th American Dental Association Annual Session and Technical Exhibition

Date: 06-09.10.05

Venue: Pennsylvania Convention Center, Philadelphia

Email: annualsession@ada.org

www.ada.org

Dentaid CPD Day

Date: 15.10.05

Venue: King's College, London

Tel: 01794324249

www.dentaid.org

BDA North of Scotland Branch Young Dentists Conference and Ceildh

Date: 22.10.05

Venue: Dundee Dental Hospital and

School, and the Apex Hotel and Spa,

Dundee

Contact: Frankie Soldani

Tel: 01382635962

DenTech China 2005

Date: 26-29.10.05

Venue: Shanghai Everbright Convention \& Exhibition Center, Shanghai

Tel: 86-21-6294 6966

Fax: 86-21-6280 0908

Email:mail@showstar.net

www.dentech.com.cn

\section{November 2005}

2nd European Congress on the Reconstruction of the Periodontally Diseased Patient

Date: 25-27.11.05

Venue: Radisson SAS Scandinavia Hotel, Copenhagen

Email: kongress@quintessenz.de www.quintessenz.de/ecrp

Greater New York Dental Meeting

Date: 25-30.11.05

Venue: New York

Email: info@gnydm.com

www.gnydm.com 


\section{Cancer treatments can damage tiny teeth}

Cancer therapies can damage children's teeth, according to research published by the University of Helsinki, Finland. Dr Päivi Hölttä, Licentiate in Dentistry, from the Institute of Dentistry at the University, studied the effects of high-dose anticancer chemotherapy and total body irradiation on the development of permanent teeth and found that cytostatic and radiation therapies administered before stem cell transplantation often damage children's permanent teeth.

The children examined in the study were treated for cancer or aplastic anaemia, had received stem cell transplantation at ages 1 to 9.4 years, preceded with a high-dose anticancer chemotherapy and, in most cases, with total body irradiation.

In her research, Dr Hölttä studied how many of the treated children lacked permanent teeth or had unusually small teeth, and how often dental roots were poorly developed.

The results indicated that $31 \%$ of the treated children lacked permanent teeth (as opposed to $8 \%$ of the Finnish population), when wisdom teeth were excluded. Lack of permanent teeth was most frequent (77\%) among children who had been less than three years old at stem cell transplantation. The highest number of missing teeth was 12 and those who had been over five years of age at stem cell transplantation lacked only wisdom teeth.

A significant finding was that a high-dose anticancer chemotherapy alone caused a lack of permanent teeth nearly as often as when combined with total body irradiation, which, however, slightly increased the number of missing teeth.

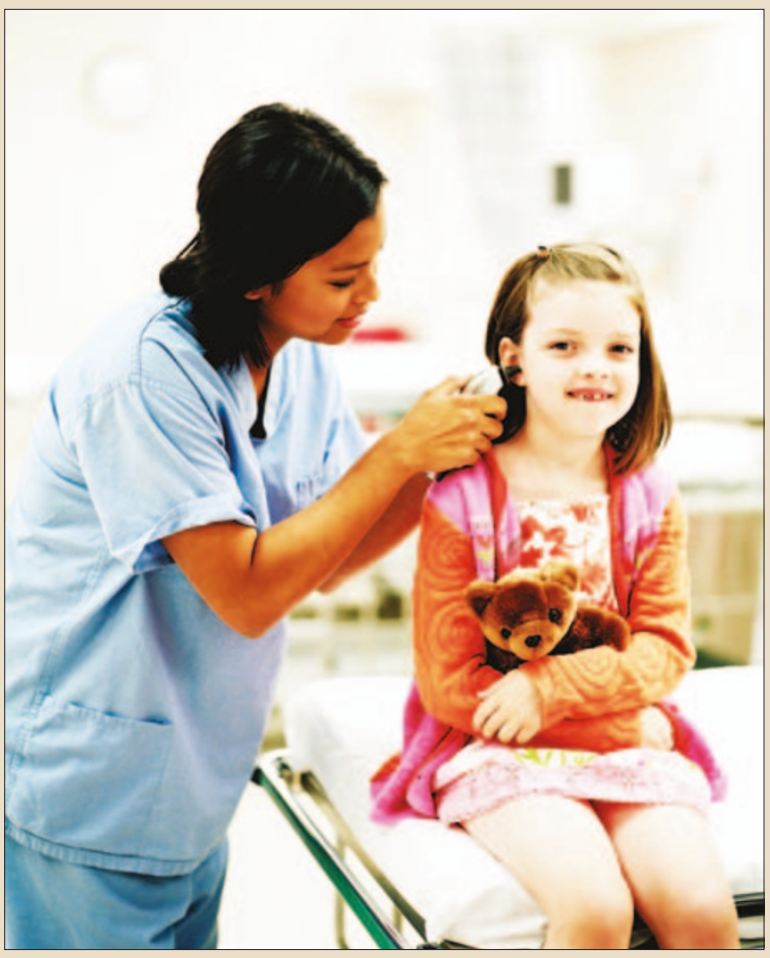

Dr Hölttä said, "We still don’t know about the long-term consequences of the treatments, which is why the monitoring of the patients should be continuous and centralised. Cooperation between specialists in children's haematology and oncology and specialists in various fields of dentistry is of fundamental importance in providing for these children the best possible dental care in the future."

\section{New child dental health taskforce launched}

The first-ever global child dental health taskforce has been established this month. The taskforce will initiate pan-European and wider global action between now and 2025 to make tangible improvements in child oral health. The initiative is backed by the World Health Organisation, the World Dental Federation and over 40 chief dental officers and leading dental figures from across the world.

Although oral health has steadily improved over the last 30 years, dental disease is still the number one disease affecting children, occurring five to eight times more frequently than asthma, the second most common chronic disease. In industrialised countries the majority of schoolchildren are affected by dental decay, disease levels being highest in the under-privileged groups. Dental disease levels are also increasing rapidly in the developing countries. The taskforce will encourage sharing of resources and best practice between international dental leaders.

The initiative comes during the UK's presidency of the European Union and reducing health inequalities is a key theme of the UK presidency. England's Chief Dental Officer Professor Raman Bedi said, "Good oral health is fundamental to good health overall. We are establishing this taskforce to improve oral health amongst children on an international level and reduce oral health inequalities. Over the past 30 years we have seen unprecedented improvements in child oral health, but far more needs to be done to tackle this easily treatable disease. The taskforce will ensure effective sharing of information on preventative measures and work to implement initiatives to improve oral health inequalities both within and between nations."

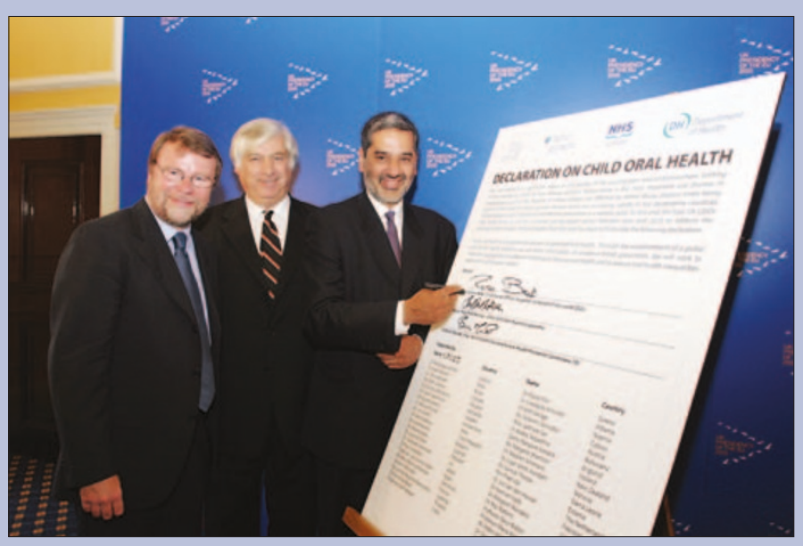

Pictured above from left to right, Professor Poul Eric Petersen, WHO Oral Health Programme, Dr Brian Mouatt, World Dental Federation (FDI) and Professor Raman Bedi, Chief Dental Officer, England.

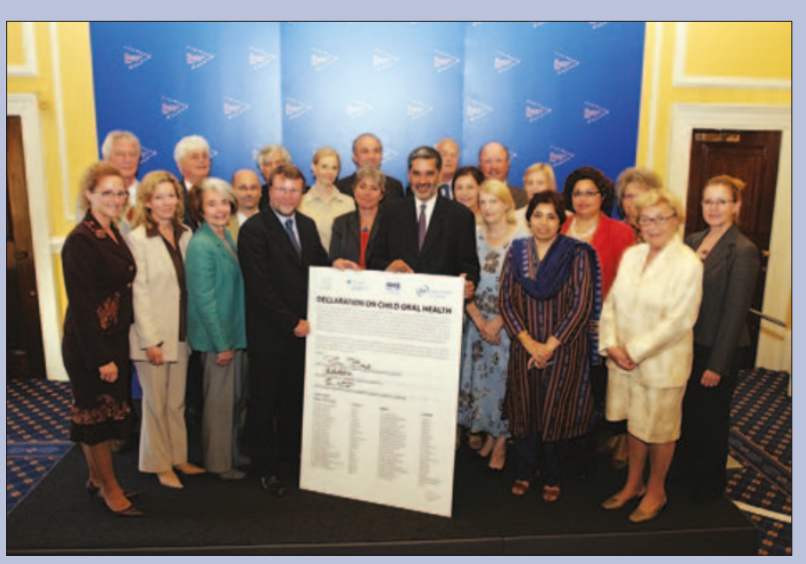




\section{Solution for sensitive teeth}

Sensitive teeth could be a thing of the past according to a solution that has been developed by scientists from Leeds University. The team has discovered that microscopic nanospheres could help dentists fill dentine tubules in teeth that make them incredibly sensitive, and that cause severe pain for millions of adults and children worldwide.

Preliminary research presented at the Institute of Physics conference EMAGNANO 2005 earlier this month shows that creating tiny spheres of a ceramic material called hydroxyapatite could be a long term solution or cure for sensitive teeth.

Jonathan Earl, David Wood and Steve Milne from the Institute of Materials Research at the University of Leeds have found that the most successful particle shape for filling dental tubules is a 'nanosphere' and are now trying to synthesize nanospheres of hydroxyapatite. Hydroxyapatite is a ceramic material which is highly compatible with teeth and bone and so is widely used by medics for bone grafts or dental coatings (because it binds strongly with the bone material).

Dr Earl and his colleagues grew hydroxyapatite at various $\mathrm{pH}$ levels to vary the constituant size of the particles. At normal $\mathrm{pH}$, it is composed of long rod-like structures but at high $\mathrm{pH}$ levels the particles of hydroxyapatite become smaller and more rounded, better for fitting inside the dentine tubules in teeth. To see whether nanospheres would be successful at filling the tubules they used commercially available silica nanospheres of around 40nm in diameter.

Dr Earl said, "We found these tiny spheres are really good at filling the channels in teeth, packing inside them quite evenly and going down the holes to a good depth. They'd be the perfect shape of particle for filling these channels and

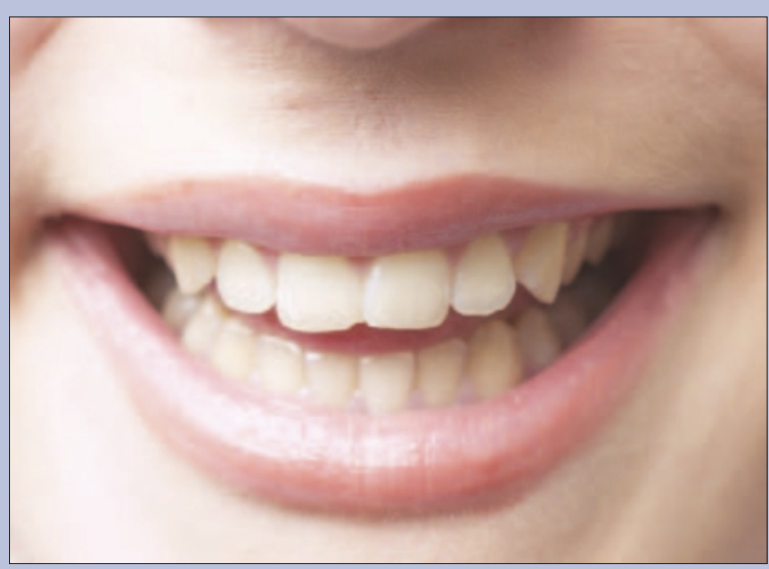
reducing or preventing the pain caused by sensitive teeth".

The next stage of their research will be to work out how to synthesise nanospheres of hydroyapatite or a combination of hydroxyapatite and fluorine which would fill the tubules and encourage re-mineralisation at the same time and so be a powerful repair tool.

\section{Over a decade of dentistry explored}

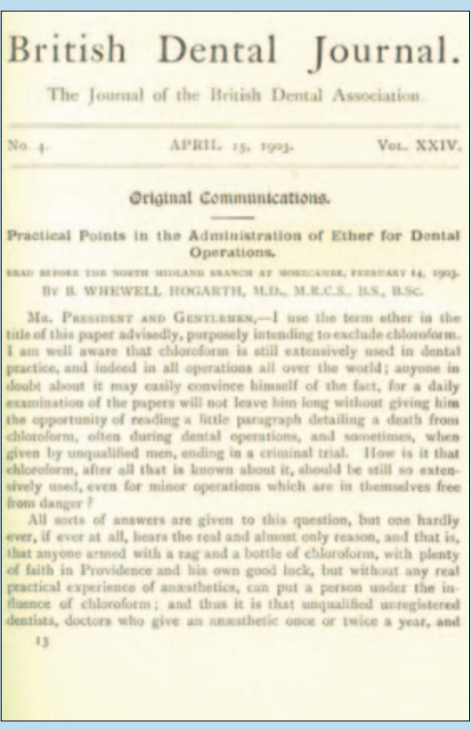

This issue of the $B D J$ features a new series which explores progress in the field of dentistry over a period of 125 years. The first part of 125 years of developments in dentistry, 1880-2005 looks at dental journals, and how dental literature developed and grew. Other areas that will be featured in the series of seven articles include law and the dental profession, dental equipment and materials, clinical dentistry, dental education, training and qualifications, general and specialist practice and war and the dental profession.

The author of the series Professor Stanley Gelbier is honorary senior research Fellow at the Wellcome Trust Centre for the History of Medicine at University College and honorary Curator of the BDA Museum. He said that it was an opportune time for dentists and other members of the team to consider how far the profession and dental care have progressed since the BDA was formed. 